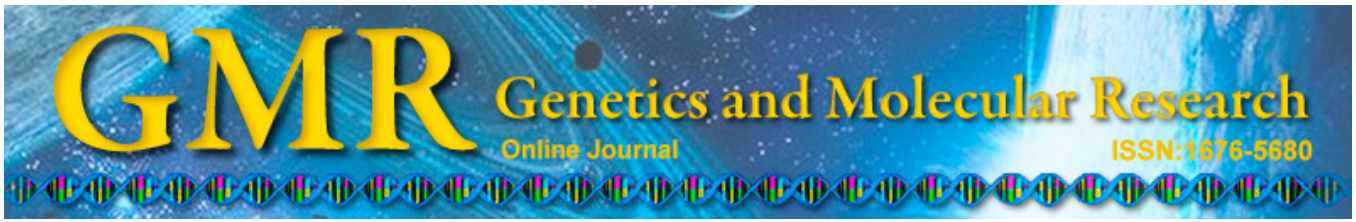

\title{
Correlation between IRGM genetic polymorphisms and Crohn's disease risk: a meta-analysis of case-control studies
}

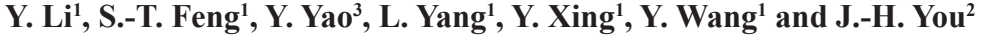 \\ ${ }^{1}$ Department of Gastroenterology, People's Hospital of Liaoning Province, \\ Shenyang, China \\ ${ }^{2}$ Department of Respiratory Medicine, People's Hospital of Liaoning Province, \\ Shenyang, China \\ ${ }^{3}$ First Department of Gastroenterology, People's Hospital of Liaoning Province, \\ Shenyang, China \\ Corresponding author: Y. Li \\ E-mail: lnph_ly@163.com
}

Genet. Mol. Res. 13 (4): 10741-10753 (2014)

Received November 8, 2013

Accepted April 28, 2014

Published December 18, 2014

DOI http://dx.doi.org/10.4238/2014.December.18.15

\begin{abstract}
This meta-analysis was performed to evaluate the relationships between single-nucleotide polymorphisms (SNPs) in the immunity-related GTPase M (IRGM) gene and the risk of Crohn's disease (CD). Eleven case-control studies were included, for a total of $5183 \mathrm{CD}$ patients and 5571 healthy controls. Three common SNPs (rs13361189 C>T, rs10065172 C $>$ T, and rs4958847 A $>\mathrm{G}$ ) in the IRGM gene were assessed. We found that the IRGM rs13361189 polymorphism was significantly associated with an increased risk of $\mathrm{CD}$ [C allele vs $\mathrm{T}$ allele: odds ratio $(\mathrm{OR})=1.30,95 \%$ confidence interval $(\mathrm{CI})=1.05-1.61$, $\mathrm{P}=0.017 ; \mathrm{CC}+\mathrm{CT}$ vs TT: $\mathrm{OR}=1.32,95 \% \mathrm{CI}=1.06-1.64, \mathrm{P}=0.013]$. However, we observed no correlation between the rs10065172 and rs4958847 polymorphisms in the IRGM gene with susceptibility to CD (all $\mathrm{P}>0.05)$. Subgroup analysis by ethnicity revealed significant associations between IRGM genetic polymorphisms and an increased risk of CD
\end{abstract}


among Caucasian populations $(\mathrm{C}$ allele $v s \mathrm{~T}$ allele: $\mathrm{OR}=1.22,95 \% \mathrm{CI}=$ $1.07-1.40, \mathrm{P}=0.004 ; \mathrm{CC}+\mathrm{CT}$ vs TT: $\mathrm{OR}=1.22,95 \% \mathrm{CI}=1.05-1.41, \mathrm{P}$ $=0.009$ ), but not among Asian populations (all $\mathrm{P}>0.05$ ). Meta-regression analysis also confirmed that ethnic differences may be an important source of heterogeneity $(\mathrm{P}=0.003)$. Our meta-analysis results indicate that the IRGM rs13361189 polymorphism contributes to the susceptibility to CD. Thus, the $I R G M$ rs 13361189 polymorphism is promising as a biomarker for early diagnosis of CD. However, the IRGM rs 10065172 and rs4958847 polymorphisms may not be the major determinants of $\mathrm{CD}$ risk.

Key words: Crohn's disease; IRGM; Single nucleotide polymorphism; Meta-analysis

\section{INTRODUCTION}

Crohn's disease (CD), an inflammatory bowel disease, is a chronic progressive destructive illness that primarily affects any part of the gastrointestinal tract from the mouth to the anus and causes a wide variety of symptoms (Beaugerie et al., 2009; Smith et al., 2009). Furthermore, the incidence and prevalence of $C D$ have increased in recent years in both adults and children (Latiano et al., 2010). Although the causes and etiology of CD are currently unknown, both genetic and environmental factors as well as immune interactions contribute to the development and progression of CD (Todd, 2010). It is well known that genetic variations in immunity-related genes influence individual susceptibility to CD (Parkes et al., 2007).

Immunity-related GTPase family M protein (IRGM), also known as interferon-inducible protein 1 (IFI1), belongs to the p47 immunity-related GTPase family and plays a crucial role in innate resistance to intracellular pathogens (Moon et al., 2013). Importantly, IRGM proteins function to regulate autophagic flux, which influences the localization of glycophorinbinding proteins and potentially other factors that direct cell-autonomous immune resistance (Traver et al., 2011). The human IRGM gene, located on chromosome 5q33.1, contains 5 exons and 4 introns (Latiano et al., 2009). Genetic mutations in IRGM may impact autophagic clearance of intracellular bacteria, lead to intracellular bacterial survival, activate the immune response, and thus increase susceptibility to CD (Henry et al., 2010; Brest et al., 2011). Therefore, we hypothesized that single-nucleotide polymorphisms (SNPs) in the IRGM gene are functional and are associated with the development of CD (Jung et al., 2012). Among these SNPs in the IRGM gene, rs13361189 $(\mathrm{C}>\mathrm{T}), \mathrm{rs} 10065172(\mathrm{C}>\mathrm{T})$, and $\mathrm{rs} 4958847(\mathrm{~A}>\mathrm{G})$ are the most common (Latiano et al., 2009; Brest et al., 2011; Gardet and Xavier, 2012). Large quantities of evidence have indicated that $I R G M$ genetic polymorphisms increase the risk of CD (Roberts et al., 2008; Wolfkamp et al., 2010), but the results of these studies have been contradictory (Meggyesi et al., 2010; Zheng and Pang, 2012). Therefore, we performed this meta-analysis to evaluate the relationships between IRGM genetic polymorphisms and CD risk.

\section{MATERIAL AND METHODS}

\section{Literature search}

The PubMed, CISCOM, CINAHL, Web of Science, Google Scholar, EBSCO, 
Cochrane Library, and CBM databases were searched from their inception through October 1, 2013 without language restrictions. The initial literature search used the following key words and MeSH terms: ["SNP" or "mutation" or "genetic polymorphism" or "variation" or "polymorphism" or "single-nucleotide polymorphism" or "variant"] and ["Crohn's disease" or "CD"] and ["human immunity-related GTPase M" or "IRGM"]. A manual search of the references of included studies was conducted to identify other potentially eligible studies.

\section{Selection criteria}

Studies included in our meta-analysis met the following criteria: 1) the study design was a clinical cohort or case-control study; 2) the study examined the relationships between IRGM genetic polymorphisms and susceptibility to $\mathrm{CD} ; 3$ ) all patients conformed to the diagnostic criteria of $\mathrm{CD}$; and 4) the study provided sufficient information regarding the frequencies of IRGM genetic polymorphisms. Studies that did not meet all of the inclusion criteria were excluded from analysis. The most recent or the largest sample size publication was included when the authors published several studies using data from the same subjects.

\section{Data extraction}

Using a standardized form, relevant data were systematically extracted from all included studies by 2 researchers. The standardized form included the following items: language of publication, publication year of article, the first author's surname, geographical location, design of study, sample size, the source of the subjects, allele frequencies, source of samples, genotyping method of SNP, and evidence of Hardy-Weinberg equilibrium (HWE) in healthy controls.

\section{Quality assessment}

We evaluated the methodological quality of the included studies according to Newcastle-Ottawa Scale (NOS) criteria (Stang, 2010). The NOS criteria included 3 aspects: 1) subject selection: 0-4 scores; 2) comparability of subject: 0-2 scores; and 3) clinical outcome: $0-3$ scores. NOS scores ranged from $0-9$; a score $\geq 7$ indicated good quality.

\section{Statistical analysis}

We performed the meta-analysis using the STATA 12.0 software (Stata Corp.; College Station, TX, USA). The odds ratios (ORs) and their 95\% confidence intervals (CIs) were estimated under different genetic models. The $Z$-test was used to estimate the statistical significance of ORs. Power calculations were conducted using PS Power and Sample Size Calculations (Dupont and Plummer Jr., 1990). The Cochran $Q$-test and the $I^{2}$ test were used to evaluate potential heterogeneity between studies (Zintzaras and Ioannidis, 2005). If the $Q$-test showed a $\mathrm{P}<0.05$ or the $I^{2}$ test showed a result $>50 \%$, indicating significant heterogeneity, the random-effect model was conducted; otherwise, the fixed-effect model was used. We also performed subgroup and meta-regression analyses to explore potential sources of heterogeneity. Sensitivity analysis was performed by omitting each study in turn to evaluate the influence of 
single studies on the overall estimate. Begger's funnel plots and the Egger linear regression test were conducted to investigate publication bias (Peters et al., 2006).

\section{RESULTS}

\section{Characteristics of the studies included}

A total of 115 articles relevant to the searched key words were initially identified. The titles and abstracts of all articles were reviewed and 53 were excluded; full texts and data integrity were then reviewed and another 51 papers were excluded. A total of 11 case-control studies were included in this meta-analysis (Roberts et al., 2008; Amre et al., 2009; Dema et al., 2009; Latiano et al., 2009; Meggyesi et al., 2010; Wolfkamp et al., 2010; Prager et al., 2012; Wang et al., 2012; Zheng and Pang, 2012; Durães et al., 2013; Moon et al., 2013). Publication years of the eligible studies ranged from 2008-2013. The selection process of the eligible studies is shown in Figure 1. The distribution of the number of topic-related studies in the electronic database for the last decade is shown in Figure 2. A total of 10,754 subjects were involved in this meta-analysis, including $5183 \mathrm{CD}$ patients and 5571 healthy controls. Three common SNPs (rs13361189 C > T, rs10065172 C $>$ T, and rs4958847 A $>\mathrm{G}$ ) in the IRGM gene were assessed. All powers for the sample size of the studies included were higher than 0.70 . Nine studies were conducted in Caucasian populations and only 2 studies were conducted in Asian populations. The TaqMan assay method was performed in 8 studies; the other 3 studies used direct sequencing methods, the polymerase chain reaction-restriction fragment length polymorphism method, and the MassArray method. SNP frequencies of healthy controls were all in HWE (all P > 0.05). NOS scores of all studies included were $\geq 6$ (moderate-high quality). The study characteristics and methodological quality are summarized in Table 1.

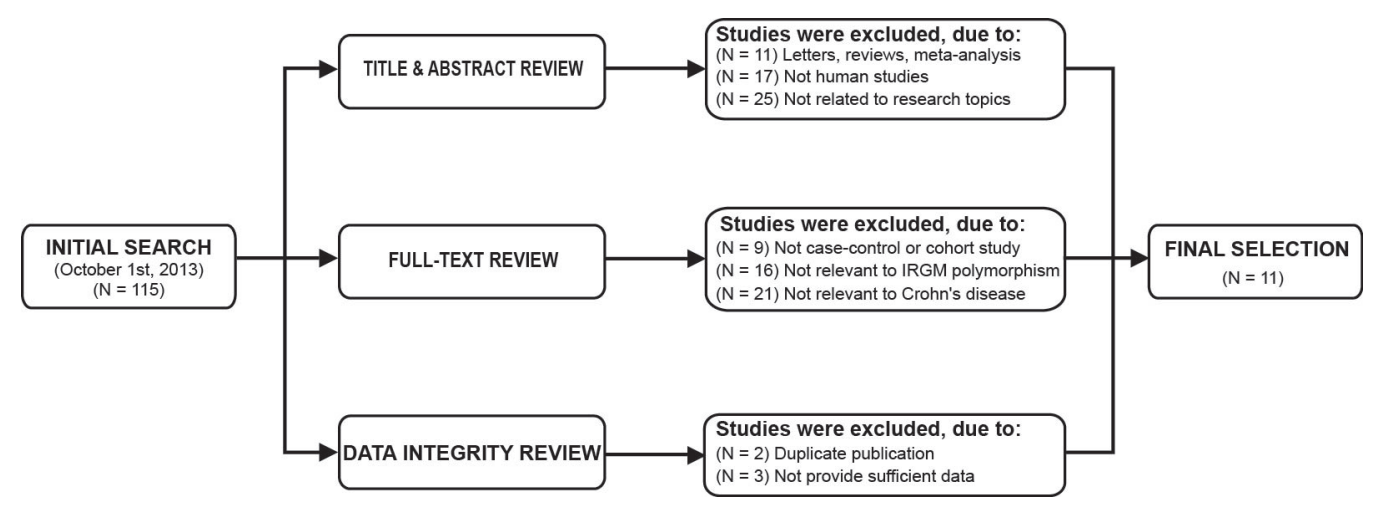

Figure 1. Flow chart of literature search and study selection.

\section{Quantitative data synthesis}

A summary of the meta-analysis findings regarding the relationships of IRGM genetic polymorphisms and susceptibility to CD is shown in Table 2. The random-effect model was conducted because significant heterogeneity existed between studies. Our meta-analysis re- 
sults revealed that the IRGM rs13361189 polymorphism was significantly associated with an increased risk of $\mathrm{CD}(\mathrm{C}$ allele $v$ s $\mathrm{T}$ allele: $\mathrm{OR}=1.30,95 \% \mathrm{CI}=1.05-1.61, \mathrm{P}=0.017 ; \mathrm{CC}+\mathrm{CT}$ vs TT: $\mathrm{OR}=1.32,95 \% \mathrm{CI}=1.06-1.64, \mathrm{P}=0.013)$. However, we observed no correlations of rs 10065172 and rs 4958847 polymorphisms in the IRGM gene with susceptibility to CD (all $\mathrm{P}$ $>0.05$; Figure $3 \mathrm{~A}$ ).

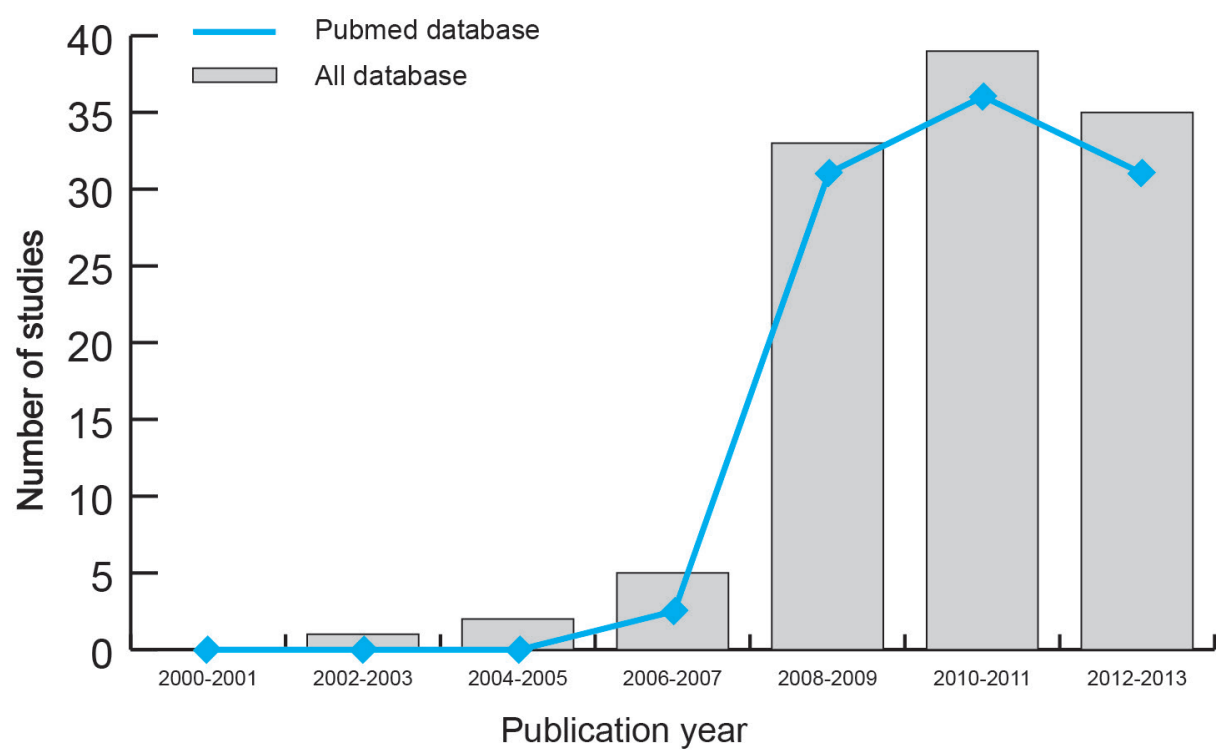

Figure 2. Distribution of the number of topic-related studies in the electronic database for the last decade.

Subgroup analysis by ethnicity suggested significant associations between IRGM genetic polymorphisms and an increased risk of $\mathrm{CD}$ among Caucasian populations $(\mathrm{C}$ allele $v s \mathrm{~T}$ allele: $\mathrm{OR}=1.22,95 \% \mathrm{CI}=1.07-1.40, \mathrm{P}=0.004 ; \mathrm{CC}+\mathrm{CT}$ vs TT: $\mathrm{OR}=1.22,95 \% \mathrm{CI}=1.05$ $1.41, \mathrm{P}=0.009$ ), but not among Asian populations (all $\mathrm{P}>0.05$; Figure $3 \mathrm{~B}$ ). Further subgroup analysis by genotyping method indicated that $I R G M$ genetic polymorphisms were significantly associated with the susceptibility to $\mathrm{CD}$ in both the TaqMan assay subgroup $(\mathrm{C}$ allele $v s \mathrm{~T}$ allele: $\mathrm{OR}=1.17,95 \% \mathrm{CI}=1.02-1.35, \mathrm{P}=0.030 ; \mathrm{CC}+\mathrm{CT}$ vs $\mathrm{TT}: \mathrm{OR}=1.19,95 \% \mathrm{CI}=1.00$ $1.42, \mathrm{P}=0.046)$ and non-TaqMan assay subgroup $(\mathrm{C}$ allele $v s \mathrm{~T}$ allele: $\mathrm{OR}=1.25,95 \% \mathrm{CI}=$ 1.01-1.55, $\mathrm{P}=0.041 ; \mathrm{CC}+\mathrm{CT}$ vs TT: $\mathrm{OR}=1.25,95 \% \mathrm{CI}=1.03-1.52, \mathrm{P}=0.023$; Figure 3C). Further stratification analysis based on sample size showed that $I R G M$ genetic polymorphisms may contribute to the susceptibility to $\mathrm{CD}$ in the large sample size subgroup (C allele $v s \mathrm{~T}$ allele: $\mathrm{OR}=1.31,95 \% \mathrm{CI}=1.06-1.62, \mathrm{P}=0.011 ; \mathrm{CC}+\mathrm{CT}$ ss $\mathrm{TT}: \mathrm{OR}=1.34,95 \% \mathrm{CI}=1.06-$ $1.69, \mathrm{P}=0.016$ ), while no correlations were observed between $I R G M$ genetic variants and $\mathrm{CD}$ risk in the small sample size subgroup (all $\mathrm{P}>0.05$; Figure 3D).

Univariate and multivariate meta-regression analyses showed that ethnicity may be the main source of heterogeneity $(\mathrm{P}=0.003$; Table 3$)$. The results of sensitivity analysis suggested that no single study could influence the overall pooled ORs (Figure 4). We found no evidence of obvious asymmetry in the Begger's funnel plots (Figure 5). The Egger test also did not display strong statistical evidence of publication bias ( $\mathrm{C}$ allele $v s$ T allele: $t=-2.60, \mathrm{P}$ $=0.019 ; \mathrm{CC}+\mathrm{CT} v s \mathrm{TT}: t=-1.54, \mathrm{P}=0.141)$. 
Y. Li et al.

10746

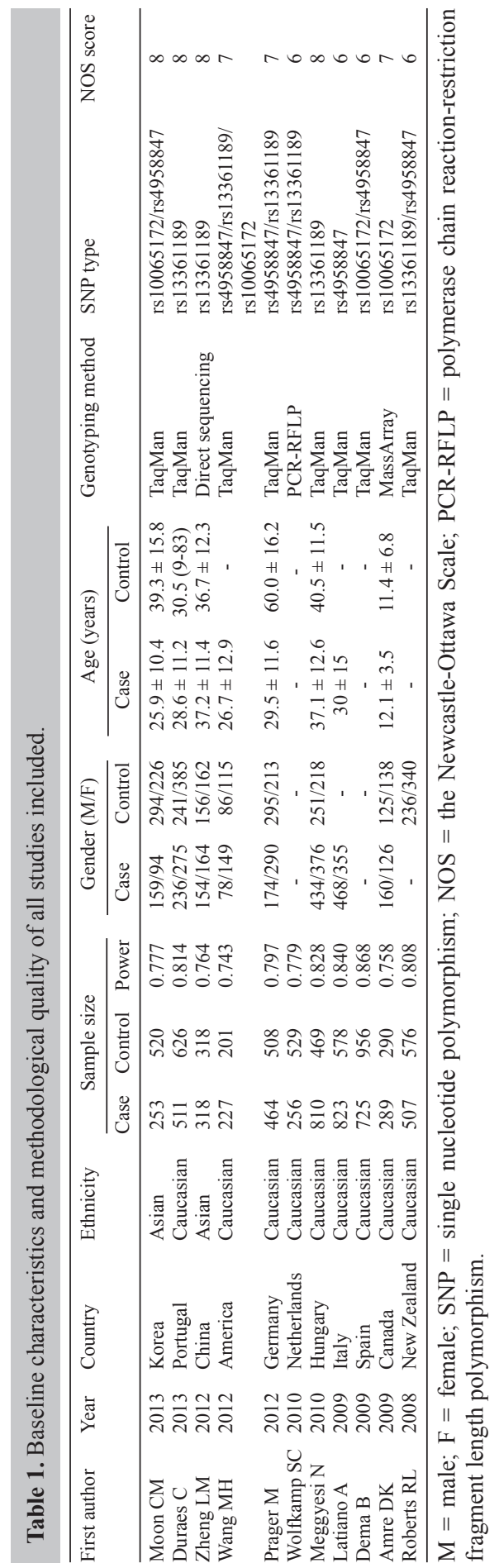




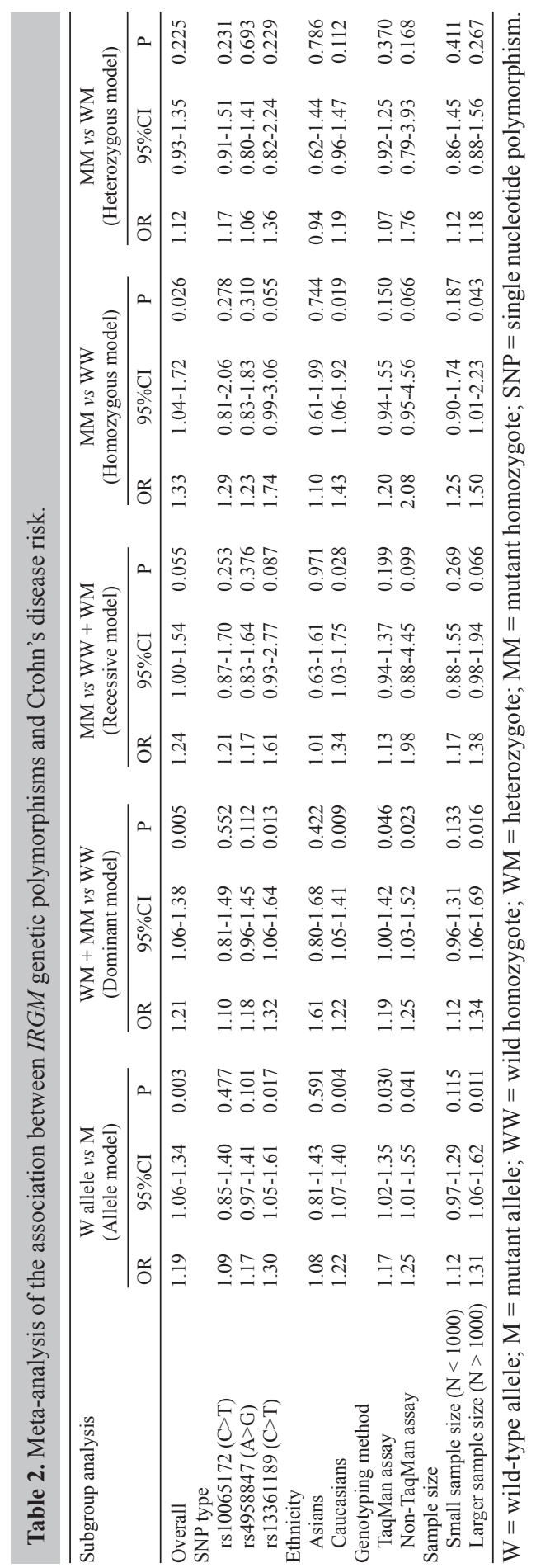


A

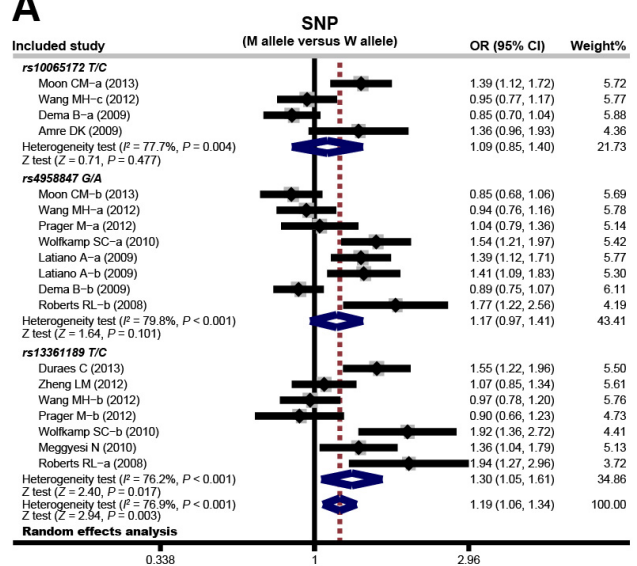

C

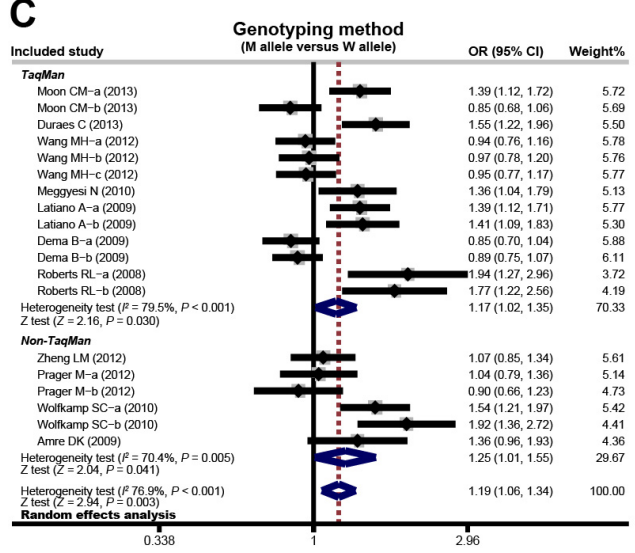

B

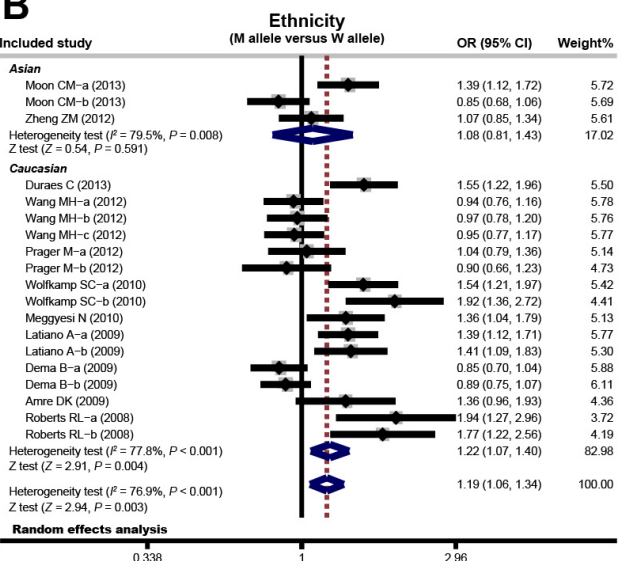

D

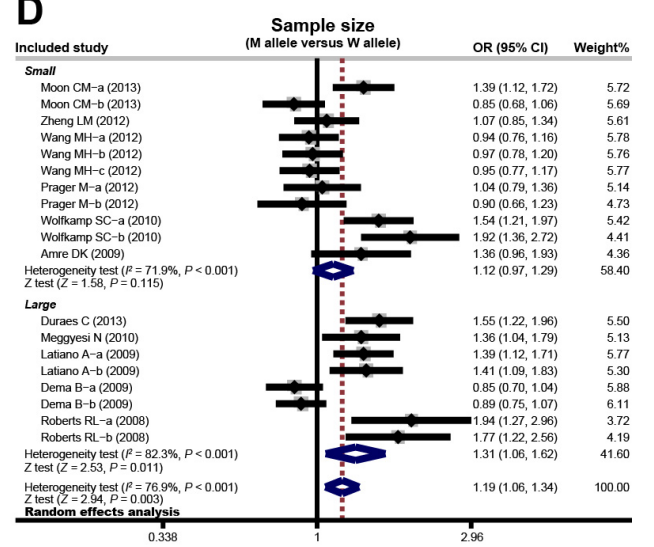

Figure 3. Subgroup analyses of the associations between IRGM genetic polymorphisms and CD risk under the allele model.

Table 3. Univariate and multivariate meta-regression analyses of potential sources of heterogeneity.

\begin{tabular}{|c|c|c|c|c|c|c|}
\hline \multirow[t]{2}{*}{ Heterogeneity factors } & \multirow[t]{2}{*}{ Coefficient } & \multirow[t]{2}{*}{ SE } & \multirow[t]{2}{*}{$Z$} & \multirow[t]{2}{*}{$P$} & \multicolumn{2}{|c|}{$95 \% \mathrm{CI}$} \\
\hline & & & & & LL & $\mathrm{UL}$ \\
\hline \multicolumn{7}{|l|}{ Publication year } \\
\hline Univariate & -0.589 & 0.039 & -1.49 & 0.137 & -0.136 & 0.019 \\
\hline Multivariate & -0.062 & 0.066 & -0.94 & 0.348 & -0.192 & 0.068 \\
\hline \multicolumn{7}{|l|}{ SNP type } \\
\hline Univariate & 0.094 & 0.091 & 1.04 & 0.289 & -0.083 & 0.272 \\
\hline Multivariate & 0.097 & 0.108 & 0.90 & 0.369 & -0.114 & 0.308 \\
\hline \multicolumn{7}{|l|}{ Ethnicity } \\
\hline Univariate & -0.258 & 0.140 & -1.84 & 0.065 & -0.532 & 0.016 \\
\hline Multivariate & -0.534 & 0.182 & -2.94 & 0.003 & -0.890 & -0.177 \\
\hline \multicolumn{7}{|l|}{ Genotyping method } \\
\hline Univariate & 0.053 & 0.150 & 0.35 & 0.724 & -0.240 & 0.346 \\
\hline Multivariate & 0.130 & 0.227 & 0.57 & 0.567 & -0.315 & 0.575 \\
\hline \multicolumn{7}{|l|}{ Sample size } \\
\hline Univariate & 0.163 & 0.136 & 1.19 & 0.232 & -0.104 & 0.429 \\
\hline Multivariate & 0.143 & 0.270 & 0.53 & 0.595 & -0.385 & 0.672 \\
\hline
\end{tabular}

$\mathrm{SE}=$ standard error; $95 \% \mathrm{CI}=95 \%$ confidence interval; $\mathrm{LL}=$ lower limit; $\mathrm{UL}=$ upper limit. 


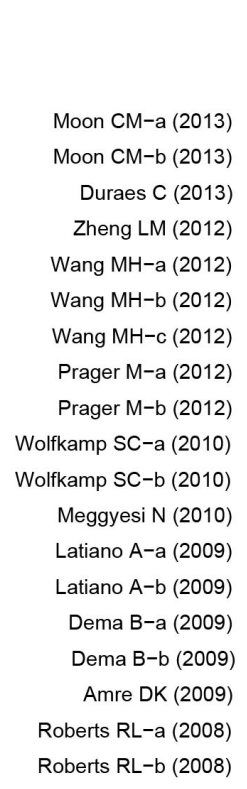

\section{$M$ allele versus $\mathbf{W}$ allele}

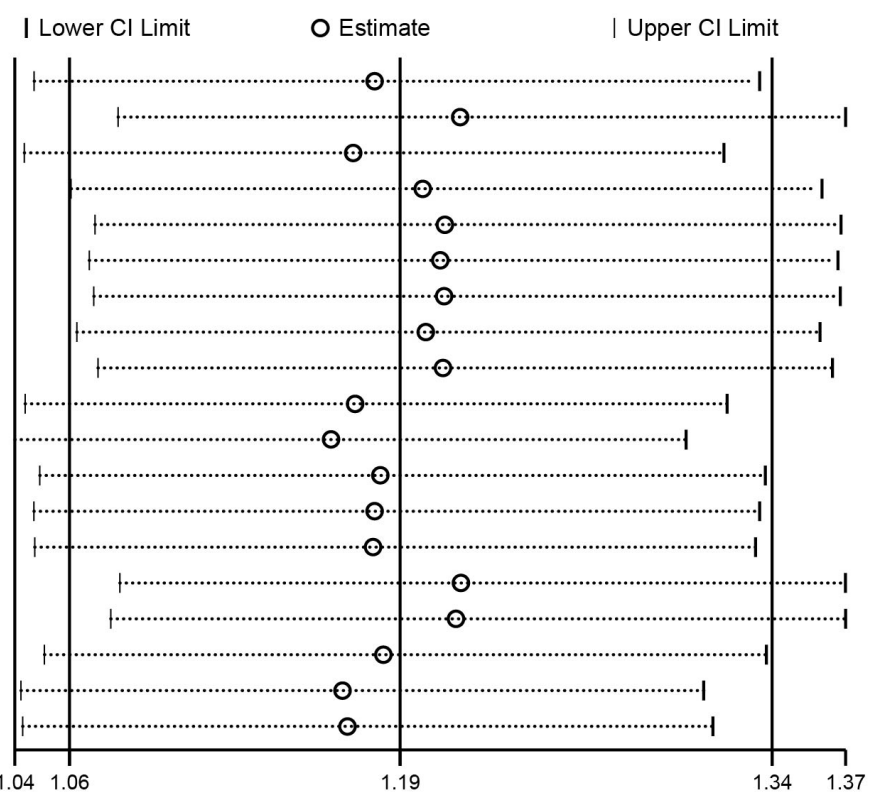

WM+MM versus WW

Lower Cl Limit O Estimate I Upper Cl Limit

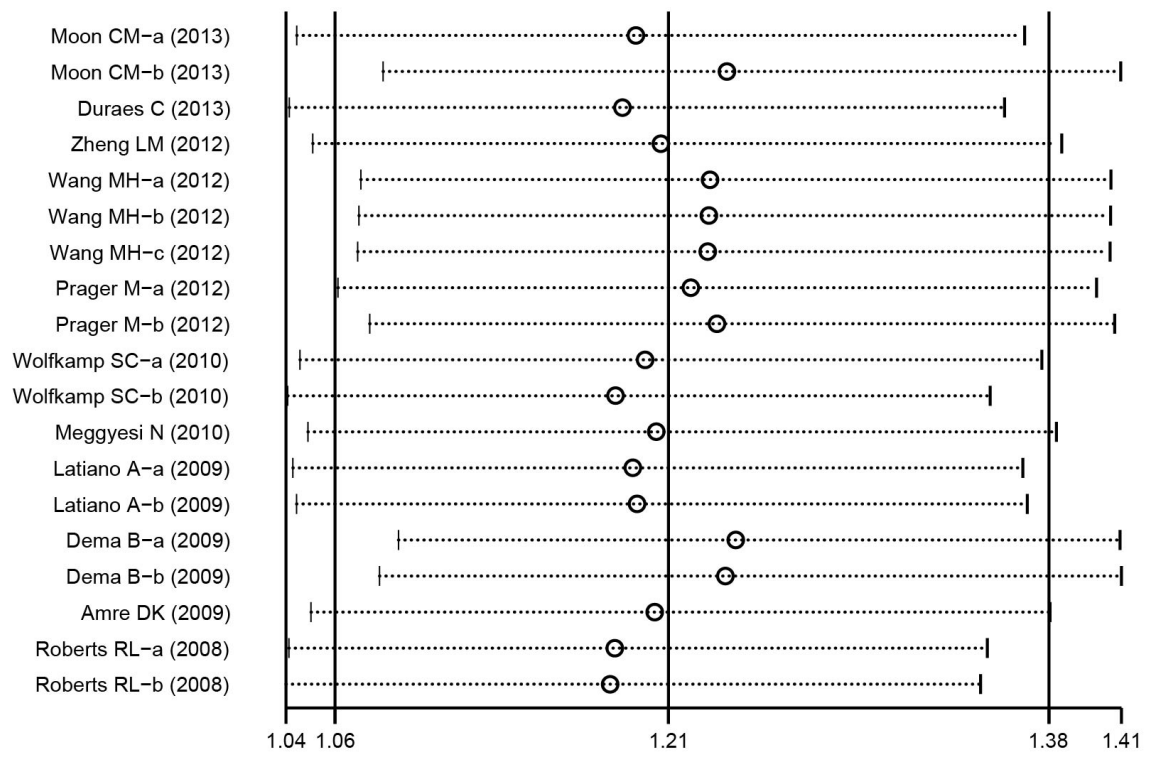

Figure 4. Sensitivity analysis of the summary odds ratio coefficients for the associations between IRGM genetic polymorphisms and $\mathrm{CD}$ risk under the allele and dominant models. $\mathrm{W}=$ wild-type allele; $\mathrm{M}=$ mutant allele; $\mathrm{WW}=$ wild homozygote; $\mathrm{WM}=$ heterozygote; $\mathrm{MM}=$ mutant homozygote . 

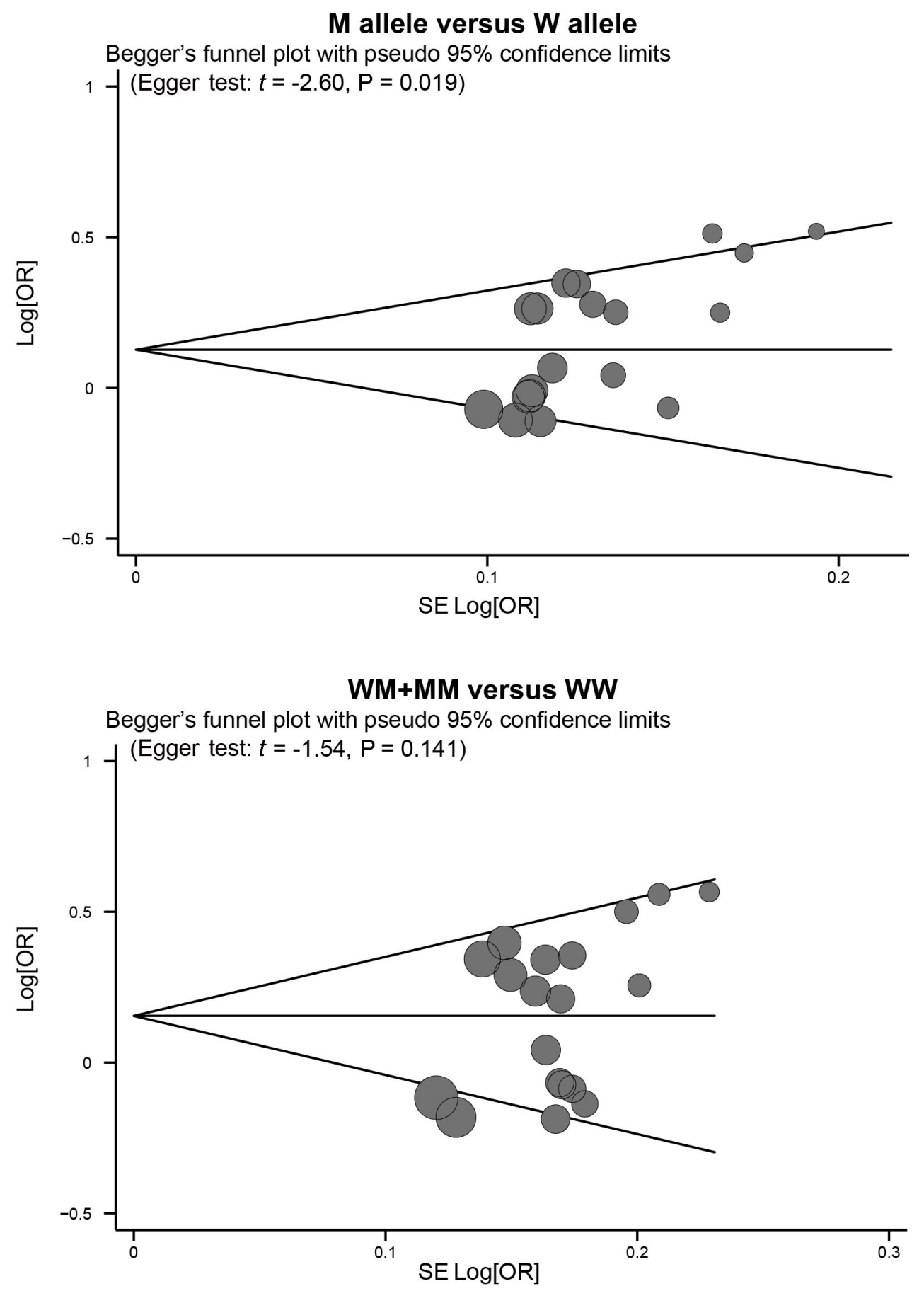

Figure 5. Begger's funnel plots and the Egger linear regression test of publication bias. $\mathrm{W}=$ wild-type allele; $\mathrm{M}=$ mutant allele; $\mathrm{WW}=$ wild homozygote; $\mathrm{WM}=$ heterozygote; $\mathrm{MM}=$ mutant homozygote . 


\section{DISCUSSION}

IRGM, a member of the immunity-related GTPases family, refers to a cell-autonomous resistance system that is essential for controlling intracellular pathogens by regulating autophagy formation (Hunn et al., 2011; Lapaquette et al., 2012; Deretic, 2012). IRGM has been indicated to act as a rheostat to fine-tune the autophagy process (Folmes et al., 2012). The regulatory pathways of autophagy integrate a wide range of stress signals that are part of CD physiopathology (Caramés et al., 2010; Deretic et al., 2013). Consequently, IRGM may particularly affect the onset, severity, and relapse of CD (Lapaquette et al., 2010). Several SNPs in the IRGM gene such as rs13361189 $(\mathrm{C}>\mathrm{T})$, rs10065172 $(\mathrm{C}>\mathrm{T})$, and rs4958847 $(\mathrm{A}>\mathrm{G})$ have been investigated previously (Waterman et al., 2011; Peter et al., 2011; Moon et al., 2013). Previous studies have shown that these 3 polymorphisms may impact the normal expression of the IRGM gene, thus contributing to the susceptibility to CD (Palomino-Morales et al., 2009; Glas et al., 2013).

In the present meta-analysis, we evaluated the relationships between IRGM genetic polymorphisms and CD risk. A total of 11 independent case-control studies were included, with a total of 10,754 subjects, including $5183 \mathrm{CD}$ patients and 5571 healthy controls. The results showed that the IRGM rs13361189 polymorphism was associated with CD risk, suggesting that the IRGM rs13361189 polymorphism may be a risk factor for susceptibility to CD. Although the exact mechanism of IRGM genetic polymorphisms in the development of CD are not clear, gene mutation and protein expression of IRGM, as an important chemokine in the pathogenesis of CD, may play a crucial role in the susceptibility to CD (Weersma et al., 2009; Brain et al., 2012). However, there were no associations between IRGM rs 10065172 and rs 4958847 polymorphisms and CD risk, suggesting that these 2 polymorphisms are not determinant factors in the pathogenesis of CD. Since heterogeneity existed in previous individual studies, subgroup analysis was carried out. Our results revealed a relationship between the IRGM rs13361189 polymorphism and an increased risk of $\mathrm{CD}$ among Caucasians, while similar associations were not observed among Asians. Geographical and ethnic factors may be responsible for individual differences in the susceptibility to CD. In addition, further subgroup analysis based on sample sizes indicated that $I R G M$ genetic polymorphisms were related to CD susceptibility in the large sample size subgroup, but not in the small sample size subgroup. There results indicated that sample size is a potential source of heterogeneity. Overall, our results were consistent with those of previous studies in that the relationships between IRGM genetic polymorphisms may be strongly linked to the development and progression of CD.

There were some limitations to this meta-analysis. First, our results may not provide sufficient statistical power to estimate the correlation between IRGM genetic polymorphisms and $\mathrm{CD}$ risk because of the relatively small sample size. Second, a meta-analysis is a retrospective study that may lead to subject selection bias, thereby affecting the reliability of our results. Third, our meta-analysis failed to obtain original data from the studies included, which may limit further evaluation of the potential roles of IRGM genetic polymorphisms in the development of CD. Importantly, the inclusion criteria of cases and controls were not well defined in all studies included, which may also have influenced our results.

In conclusion, the results of our meta-analysis suggest that the IRGM rs13361189 polymorphism contributes to the susceptibility to CD. Thus, the $I R G M$ rs 13361189 polymorphism is promising as a biomarker for early diagnosis of CD. However, the IRGM rs 10065172 and rs4958847 polymorphisms may not be the major determinants of CD risk. Because of the limitations described above, further detailed studies are required to confirm our findings. 


\section{Conflicts of interest}

The authors declare no conflict of interest.

\section{ACKNOWLEDGMENTS}

We would like to acknowledge the reviewers for their helpful comments on this paper. We would also like to thank our colleagues at the Department of Gastroenterology, People's Hospital of Liaoning Province.

\section{REFERENCES}

Amre DK, Mack DR, Morgan K, Krupoves A, et al. (2009). Autophagy gene ATG16L1 but not IRGM is associated with Crohn's disease in Canadian children. Inflamm. Bowel Dis. 15: 501-507.

Beaugerie L, Brousse N, Bouvier AM, Colombel JF, et al. (2009). Lymphoproliferative disorders in patients receiving thiopurines for inflammatory bowel disease: a prospective observational cohort study. Lancet 374: 1617-1625.

Brain O, Cooney R, Simmons A and Jewell D (2012). Functional consequences of mutations in the autophagy genes in the pathogenesis of Crohn's disease. Inflamm. Bowel Dis. 18: 778-781.

Brest P, Lapaquette P, Souidi M, Lebrigand K, et al. (2011). A synonymous variant in IRGM alters a binding site for miR196 and causes deregulation of IRGM-dependent xenophagy in Crohn's disease. Nat. Genet. 43: 242-245.

Caramés B, Taniguchi N, Otsuki S, Blanco FJ, et al. (2010). Autophagy is a protective mechanism in normal cartilage, and its aging-related loss is linked with cell death and osteoarthritis. Arthritis Rheum. 62: 791-801.

Dema B, Fernández-Arquero M, Maluenda C, Polanco I, et al. (2009). Lack of association of NKX2-3, IRGM, and ATG16L1 inflammatory bowel disease susceptibility variants with celiac disease. Hum. Immunol. 70: 946-949.

Deretic V (2012). Autophagy as an innate immunity paradigm: expanding the scope and repertoire of pattern recognition receptors. Curr. Opin. Immunol. 24: 21-31.

Deretic V, Saitoh T and Akira S (2013). Autophagy in infection, inflammation and immunity. Nat. Rev. Immunol. 13: $722-737$.

Dupont WD and Plummer WD Jr (1990). Power and sample size calculations. a review and computer program. Control Clin. Trials 11: 116-128.

Durães C, Machado JC, Portela F, Rodrigues S, et al. (2013). Phenotype-genotype profiles in Crohn's disease predicted by genetic markers in autophagy-related genes (GOIA study II). Inflamm. Bowel Dis. 19: 230-239.

Folmes CD, Dzeja PP, Nelson TJ and Terzic A (2012). Metabolic plasticity in stem cell homeostasis and differentiation. Cell. Stem Cell 11: 596-606.

Gardet A and Xavier RJ (2012). Common alleles that influence autophagy and the risk for inflammatory bowel disease. Curr. Opin. Immunol. 24: 522-529.

Glas J, Seiderer J, Bues S, Stallhofer J, et al. (2013). IRGM variants and susceptibility to inflammatory bowel disease in the German population. PLoS One 8: e54338.

Henry SC, Traver M, Daniell X, Indaram M, et al. (2010). Regulation of macrophage motility by Irgm1. J. Leukoc. Biol. 87: 333-343.

Hunn JP, Feng CG, Sher A and Howard JC (2011). The immunity-related GTPases in mammals: a fast-evolving cellautonomous resistance system against intracellular pathogens. Mamm. Genome 22: 43-54.

Jung C, Colombel JF, Lemann M, Beaugerie L, et al. (2012). Genotype/phenotype analyses for 53 Crohn's disease associated genetic polymorphisms. PLoS One 7: e52223.

Lapaquette P, Glasser AL, Huett A, Xavier RJ, et al. (2010). Crohn's disease-associated adherent-invasive E. coli are selectively favoured by impaired autophagy to replicate intracellularly. Cell. Microbiol. 12: 99-113.

Lapaquette P, Brest P, Hofman P and Darfeuille-Michaud A (2012). Etiology of Crohn's disease: many roads lead to autophagy. J. Mol. Med. 90: 987-996.

Latiano A, Palmieri O, Cucchiara S, Castro M, et al. (2009). Polymorphism of the IRGM gene might predispose to fistulizing behavior in Crohn's disease. Am. J. Gastroenterol. 104: 110-116.

Latiano A, Palmieri O, Corritore G, Valvano MR, et al. (2010). Variants at the 3p21 locus influence susceptibility and phenotype both in adults and early-onset patients with inflammatory bowel disease. Inflamm. Bowel Dis. 16: 11081117. 
Meggyesi N, Kiss LS, Koszarska M, Bortlik M, et al. (2010). NKX2-3 and IRGM variants are associated with disease susceptibility to IBD in Eastern European patients. World J. Gastroenterol. 16: 5233-5240.

Moon CM, Shin DJ, Kim SW, Son NH, et al. (2013). Associations between genetic variants in the IRGM gene and inflammatory bowel diseases in the Korean population. Inflamm. Bowel Dis. 19: 106-114.

Palomino-Morales RJ, Oliver J, Gómez-Garcia M, López-Nevot MA, et al. (2009). Association of ATG16L1 and IRGM genes polymorphisms with inflammatory bowel disease: a meta-analysis approach. Genes Immun. 10: 356-364.

Parkes M, Barrett JC, Prescott NJ, Tremelling M, et al. (2007). Sequence variants in the autophagy gene IRGM and multiple other replicating loci contribute to Crohn's disease susceptibility. Nat. Genet. 39: 830-832.

Peter I, Mitchell AA, Ozelius L, Erazo M, et al. (2011). Evaluation of 22 genetic variants with Crohn's disease risk in the Ashkenazi Jewish population: a case-control study. BMC Med. Genet. 12: 63.

Peters JL, Sutton AJ, Jones DR, Abrams KR, et al. (2006). Comparison of two methods to detect publication bias in metaanalysis. JAMA 295: 676-680.

Prager M, Buttner J, Haas V, Baumgart DC, et al. (2012). The JAK2 variant rs10758669 in Crohn's disease: altering the intestinal barrier as one mechanism of action. Int. J. Colorectal Dis. 27: 565-573.

Roberts RL, Hollis-Moffatt JE, Gearry RB, Kennedy MA, et al. (2008). Confirmation of association of IRGM and NCF4 with ileal Crohn's disease in a population-based cohort. Genes Immun. 9: 561-565.

Smith AM, Rahman FZ, Hayee B, Graham SJ, et al. (2009). Disordered macrophage cytokine secretion underlies impaired acute inflammation and bacterial clearance in Crohn's disease. J. Exp. Med. 206: 1883-1897.

Stang A (2010). Critical evaluation of the Newcastle-Ottawa scale for the assessment of the quality of nonrandomized studies in meta-analyses. Eur. J. Epidemiol. 25: 603-605.

Todd JA (2010). D'oh! genes and environment cause Crohn's disease. Cell 141: 1114-1116.

Traver MK, Henry SC, Cantillana V, Oliver T, et al. (2011). Immunity-related GTPase M (IRGM) proteins influence the localization of guanylate-binding protein 2 (GBP2) by modulating macroautophagy. J. Biol. Chem. 286: 3047130480.

Wang MH, Okazaki T, Kugathasan S, Cho JH, et al. (2012). Contribution of higher risk genes and European admixture to Crohn's disease in African Americans. Inflamm. Bowel Dis. 18: 2277-2287.

Waterman M, Xu W, Stempak JM, Milgrom R, et al. (2011). Distinct and overlapping genetic loci in Crohn's disease and ulcerative colitis: correlations with pathogenesis. Inflamm. Bowel Dis. 17: 1936-1942.

Weersma RK, Stokkers PC, Cleynen I, Wolfkamp SC, et al. (2009). Confirmation of multiple Crohn's disease susceptibility loci in a large Dutch-Belgian cohort. Am. J. Gastroenterol. 104: 630-638.

Wolfkamp SC, Te Velde AA, Weersma RK, Ponsioen CY, et al. (2010). Is there a role for Crohn's disease-associated autophagy genes ATG16L1 and IRGM in formation of granulomas? Eur. J. Gastroenterol. Hepatol. 22: 933-937.

Zheng LM and Pang Z (2012). Association of IRGM and ATG16L1 gene polymorphisms with Crohn's disease in Chinese Han population. Chin. J. Gastroenterol. Hepatol. 16: 437-440.

Zintzaras E and Ioannidis JP (2005). HEGESMA: genome search meta-analysis and heterogeneity testing. Bioinformatics 21: 3672-3673. 